\title{
A FORMAÇ̃̃O DE PROFESSORES DE CIÊNCIAS NA PERSPECTIVA INTERDISCIPLINAR SOBRE A FLUTUAÇ̃̃O PARA VIDA NO PLANETA: PELOS CAMINHOS DA CO-DOCÊNCIA
}

\author{
ARMANDO GIL FERREIRA DOS SANTOS ${ }^{*}$ \\ https://orcid.org/0000-0003-4249-7839 \\ GLORIA REGINA PESSOA CAMPELLO QUEIROZ "** \\ https://orcid.org/0000-0003-1029-3014 \\ PATRÍCIA DOMINGOS ${ }^{11{ }^{* * *}}$ \\ https://orcid.org/0000-0002-2056-3674 \\ GISELLE FAUR DE CASTRO CATARINO $" 1 * \cdots$ \\ https://orcid.org/0000-0002-0490-140X
}

RESUMO: A formação de professores tem sido discutida procurando destacar as suas exigências legais, as responsabilidades do futuro profissional docente no atual contexto escolar e como essa formação é oportunizada nas universidades e demais instituições de ensino superior. Apresentamos nesta investigação, na forma de um estudo de caso, os aspectos que potencializam a co-docência na formação de professores e as possibilidades para o desenvolvimento de práticas docentes na perspectiva interdisciplinar, trazendo um exemplo sobre a importância da flutuação para a vida no planeta. Para auxiliar a compreensão dos conceitos que permeiam essa investigação, buscamos dialogar com alguns autores, como: Shulman, Roth e Boyd, Pombo e Bakhtin. Os nossos sujeitos de pesquisa que viabilizaram a triangulação dos dados coletados são duas professoras formadoras, sendo uma delas de Física e a outra de Biologia e dezessete licenciandos dos cursos de Biologia, Física e Pedagogia, reunidos em uma disciplina eletiva. Utilizamos, como percurso metodológico, os recursos da videogravação das aulas em ação co-docente, junto aos licenciandos, tendo o laboratório LIEC de uma universidade pública do Rio de Janeiro como ambiente de formação inicial. A partir dos dados constituíram-se episódios que explicitam momentos de coaprendizagem entre os formadores e entre os discentes das diferentes áreas e que são analisados à luz das ideias de Bakhtin.

Palavras-chave: Formação de professores. Interdisciplinaridade. Co-docência. Ensino de Ciências. Análise de discurso.

\footnotetext{
' Universidade Unigranrio, Rio de Janeiro, RJ - Brasil.

" Universidade do Estado do Rio de Janeiro, Rio de Janeiro, RJ - Brasil.

II Universidade do Estado do Rio de Janeiro, Instituto de Biologia, Rio de Janeiro, RJ - Brasil.
}

Mestre em Ensino de Ciências pela
Unigranrio. Doutorando em Ciência,
Tecnologia e Educação pelo Programa de
Pós-Graduação em Ciência, Tecnologia e
Educação - PPCTE/CEFET - RJ. Professor
de Física da Fundacão Bradesco. Grupo
de Pesquisa: Teoria da Atividade.
E-mail: < gilarm@gmail.com>.
'. Doutora em Educação pela PUC - RJ.
Professora Adjunta da Universidade do
Estado do Rio de Janeiro/ Instituto de
Física (UERJ). Professora Permanente
do Programa de Pós-Graduação em
Ciência, Tecnologia e Educação -
PPCTE/CEFET - RJ. Grupo de Pesquisa:
Formação de Professores.
E-mail: < gloriapcq@gmail.com>.
Fisica e Formação de Professores.
E-mail: < gisellefaur@gmail.com>.

"Mestre em Ensino de Ciências pela Pós-Graduação em Ciência, Tecnologia Educação - PPCTE/CEFET - RJ. Professor de Pesquisa: Teoria da Atividade. E-mail:<gilarm@gmail.com> ica (UERJ). Professora Permanent do Programa de Pós-Graduação em Ciencia, Tecnologia e Educação Formação de Professores.
FJ. Grupo de Pesquisa: E-mail:<gloriapcq@gmail.com>

Doutora em Ciências (Biotecnologia Vegetal) pela Universidade Federa do Rio de Janeiro. Professora Adjunta UERJ. Coordenação de Biodiversidade do Programa de Mestrado Profissional em Rede Nacional de Ensino de Biologia - ProfBio

.** Doutora em Educação pela Universidade ederal Fluminense (UFF-RJ). Professora Adjunta da Universidade do Estado do Pós-Graduação em Ensino das Ciência da Unigranrio - PPGEC/UNIGRANRIO de Pós-Graduação em Ciência Grupo de Pesquisa: Ensino de E-mail:<gisellefaur@gmail.com >. 


\section{LA FORMACIÓN DE PROFESORES DE CIENCIAS EN LA PERSPECTIVA INTERDISCIPLINARIA A RESPECTO DE LA FLUCTUACIÓN PARA LA VIDA EN EL PLANETA: POR LOS CAMINOS DE LA CO-DOCENCIA}

RESUMEN: Se viene discutiendo la formación de profesores buscando destacar las exigencias legales, las responsabilidades del futuro profesional docente en el actual contexto escolar y cómo se da oportunidad a esa formación en las universidades y demás instituciones de enseñanza superior. Presentamos en esta investigación, en forma de análisis de caso, los aspectos que potenciaron la co-docencia en la formación de profesores y las posibilidades para el desarrollo de prácticas docentes en la perspectiva interdisciplinaria, presentando un ejemplo acerca de la importancia de la fluctuación para la vida en el planeta. Para colaborar en la comprensión de los conceptos que permean esa investigación, buscamos dialogar con algunos autores, como Shulman, Roth y Boyd, Pombo y Bakhtin. Nuestros sujetos de investigación que hicieron viable la triangulación de los datos recolectados son dos profesoras formadoras, una de ellas de Física y la otra de Biología, y diecisiete estudiantes de las carreras de Biología, Física y Pedagogía, reunidos en una asignatura electiva. Utilizamos como itinerario metodológico los recursos de la videograbación de las clases en acción co-docente, junto con los estudiantes, y se usó el laboratorio LIEC de una universidad pública de Río de Janeiro como ambiente de formación inicial. A partir de los datos se constituyeron episodios que explicitan momentos de coaprendizaje entre los formadores y entre los discentes de las diferentes áreas y que son analizados desde las ideas de Bakhtin.

Palabras clave: Formación de profesores; Interdisciplinariedad; Co-docencia; Enseñanza de Ciencias; Análisis del discurso.

\section{THE TRAINING OF SCIENCE TEACHERS ON INTERDISCIPLINARY PERSPECTIVE ABOUT FLOATING FOR LIFE ON THE PLANET: THROUGH CO-TEACHING ROUTES}

ABSTRACT: The initial teaching education has been discussed in order to highlight their legal requirements, the future responsibilities of professional teacher in the current school context and how this education is offered at the universities and other similar institutions. We present in this research, in the form of a case study, the aspects that potentiate co-teaching in teacher initial education and the possibilities for the development of teaching practices in the interdisciplinary perspective, providing an example on the importance of fluctuation for life on the planet. To help the understanding of the concepts that permeate this research, we seek to dialogue with some authors, such as: Shulman, Roth and Boyd, Pombo and Bakhtin. Our research subjects, who enabled the triangulation of the data collected, are two university teachers, one of them in Physics and the other in Biology and seventeen graduates of the Biology, Physics and Pedagogy courses, gathered in an elective discipline. We used, as a methodological course, the video-recording resources of the classes in co-teaching action, together with the students, and the LIEC laboratory of a public university in Rio de Janeiro as an initial education environment. From the data, were constituted some episodes that explain moments of co-learning between the teachers with the students and among them, of the different areas, and analyzed in the light of the ideas of Bakhtin.

Keywords: Teacher initial education. Interdiscipinarity. Co-teaching. Science teaching. Discourse analysis. 
A formação de professores de Ciências na perspectiva interdisciplinar sobre a

flutuação para vida no planeta: pelos caminhos da docência

\section{INTRODUÇÃO}

No contexto histórico atual, os desafios nas estruturas dos cursos para formação de professores passam por uma série de questões relacionadas aos aspectos políticos das resoluções oficiais, aos recursos institucionais direcionados aos cursos de licenciatura e às intenções educacionais depositadas nas práticas docentes mais autônomas e críticas. Pretto (2017) defende a necessidade de uma mudança curricular nos cursos de formação de professores na qual se desenvolvam estudos comprometidos com a contemporaneidade de forma coletiva, envolvendo todos os alunos de licenciatura da instituição, promovendo interações entre licenciandos de diferentes áreas do conhecimento, levando-os a vivenciar na universidade um ambiente interdisciplinar que os prepare para agir de modo não fragmentado ao atuarem nas escolas como profissionais da educação.

Inicialmente, buscamos alguns autores que contribuem para a reflexão sobre a educação científica e defendem o papel fundamental do professor pesquisador-reflexivo (SCHÖN, 2000) para entender a importância da ciência, como: Roitman (2007) que se refere a essa educação como uma condição para o desenvolvimento da capacidade de resolver problemas e tomar decisões com base em dados e informações; Chassot (2006) que destaca a educação científica como facilitador na leitura da realidade e a capacidade de transformar o mundo para melhor; Cachapuz et al. (2005) que entendem a educação científica como o envolvimento de professores na construção do conhecimento, aproximando sua atividade científica dos problemas da realidade; Cachapuz et al. (2004) que consideram que os conhecimentos construídos servirão de base à reflexão na abordagem CTS (Ciência, Tecnologia, Sociedade), bem como as inter-relações com o meio ambiente para que os alunos possam agir e decidir responsavelmente e que lhes permitam o desenvolvimento de atitudes e valores sobre as situaçõesproblema; Gil-Pérez e Carvalho (1993, p. 47) que destacam a possibilidade da "compreensão profunda da matéria a ser ensinada e da própria natureza da ciência".

Sob um ponto de vista que abarque os autores citados e muitos outros, entendemos que as questões relacionadas ao papel do professor pesquisadorreflexivo de ciências pressupõem a necessidade de pensar e repensar as possibilidades sobre a sua própria prática de forma inovadora, tornando-a mais interdisciplinar, de forma a dar conta de uma maior aproximação com a vida, atendendo ainda às demandas atuais dos próprios professores já em serviço, uma vez que:

a aspiração interdisciplinar emergente entre os professores corresponde ao desejo de uma prática de ensino que aponte no sentido da articulação e do cruzamento dos saberes disciplinares, que suscite a confluência de perspectivas para o estudo de problemas concretos, que restitua ao objecto de experiência comum a sua dignidade enquanto objeto de estudo, que possibilite alguma economia de esforços e até mesmo uma melhor $<<$ gestão de recursos $>>$, por exemplo, no que diz respeito ao controlo de repetições fastidiosas, à análise de dados, à utilização de instrumentos ou à recolha de informação proveniente de diversas disciplinas. (POMBO, 2002, p. 237).

Como forma de colocar currículos mais interdisciplinares em prática nas salas de aula de todos os níveis de ensino, concordamos com Roth e Boyd 
(1999) que a co-docência seja uma forma de agir entre pares de diferentes disciplinas, possibilitando a coaprendizagem desses docentes e de seus alunos, numa abordagem interdisciplinar, desde os cursos de licenciatura até os de nível fundamental e médio nas escolas. Seguindo nessa direção, outra pergunta se faz necessária: Como surge a co-docência?

Com esta pergunta, abrimos espaço para conjecturas e nos permitimos responder metaforicamente: professores possuem um certo "aroma agradável que está impregnado na crença e no desejo, com o poder para atrair outros pelo mesmo cheiro". Poderíamos adjetivar que esse fenômeno é marcado por empatia, sintonia, afinidade, mas que é humano e acontece a partir de inúmeras possibilidades e condições do tempo e do espaço disponíveis para que esses dois sujeitos atuem juntos. Em tese, essa é uma das condições favoráveis para que aconteça o ato da co-docência como prática de ensino.

Assim, nosso objetivo neste trabalho é analisar de que maneira a codocência pode contribuir para a aprendizagem de professores formadores e licenciandos a partir de diálogos interdisciplinares.

Esse artigo traz resultados de uma investigação mais ampla em andamento que tem como objetivo identificar representações que os professores formadores desenvolvem na universidade. $\mathrm{O}$ caso aqui trazido ocorreu durante uma prática de ensino interdisciplinar, destinada a licenciandos dos cursos de Física, Biologia e Pedagogia, caracterizando o trabalho desenvolvido em co-docência a partir de uma sequência didática intitulada "Flutuação dos corpos e a vida" (QUEIROZ e DOMINGOS, 2017).

Se a escola é o espaço que oportuniza o trabalho com objetivos de alcançar uma educação para formar cidadãos, cabe-nos trabalhar para que os saberes disciplinares e instituídos nos currículos encontrados na maioria das escolas possibilitem a realização de pontes para o trabalho interdisciplinar, pois cada vez mais as situações-problema da nossa sociedade vêm exigindo ações conjuntas de diversos atores que operam em diferentes áreas do conhecimento. Nesse sentido, no âmbito da formação docente, buscamos dialogar com Castro e Queiroz (2007) quando destacam que:

[...] formar um Professor é também formar um Educador, alguém que seja capaz de perceber as oportunidades de utilizar e realizar projetos sob diferentes enfoques e buscar soluções inovadoras diante de situações escolares concretas. [...] (p. 4).

No caso aqui estudado, a co-docência caminhou de mãos dadas com a interdisciplinaridade para mostrar aos professores em formação possibilidades do trabalho integrado na perspectiva de projetos sobre temas relevantes e ainda permitir que seus formadores pudessem refletir sobre a potencialidade e os obstáculos de suas próprias práticas, desenvolvendo coaprendizagens durante o processo vivido.

\section{PERCURSO METODOLÓGICO}

O tema da sequência didática desenvolvida ressaltou a vida no planeta, logo as questões relacionadas a ele, em todas as suas dimensões, suscitaram a 
interação entre diversas áreas do conhecimento. Nesse estudo, realizamos um recorte para mostrar as possibilidades de duas áreas do conhecimento, a Física e a Biologia, integradas pela co-docência, estabelecerem elementos que promovam a aproximação entre as áreas de educação em Ciências e em Direitos Humanos. Fazenda (2014) nos permite perceber essa aproximação quando evidencia a impossibilidade de pensarmos em Direitos Humanos sem considerar a evolução histórico-crítica das disciplinas Didática e Prática de Ensino:

Trata-se assim o ato educativo escolar numa dimensão complexa e interligada de diferentes componentes e de diferentes regulamentações. Sua transmissão apenas parte de um conteúdo disciplinar pré-determinado, porém amplia-se numa dimensão planetária de mundo \{Prática\} onde os estudos encontram-se sempre numa dimensão de esboços inacabados de um design de projeto que se altera em seu desenvolvimento ao tocar o Humano. (FAZENDA, 2014, p. 6).

Para desenvolver o tema Flutuação e Vida (QUEIROZ e DOMINGOS, 2017) junto aos alunos, as doze horas-aula da sequência didática foram divididas em quatro encontros semanais de três horas-aula cada. As professoras formadoras construíram os seus planos de aula segundo a abordagem PCK de Shulman (1987), que considera as representações do conteúdo específico e as estratégias didáticas, por um lado, e o entendimento das dificuldades de aprendizagem e as concepções dos estudantes de um conteúdo por outro.

As formadoras utilizaram recursos de tecnologia, como computadores, projetores digitais, slides e vídeos, procurando apresentar, no início das aulas, disparadores de interesse, com questionamentos orais e por escrito diante de imagens ou dados que estimularam a interação dos alunos e a troca dos conhecimentos trazidos de suas áreas de formação inicial. A dinâmica expositiva nas aulas era feita pelas formadoras com elementos apresentados em cada discurso individual, disciplinar ou já interdisciplinar, que se complementavam um ao outro, respeitados por um espaço e tempo harmônicos.

Em cada encontro, os licenciandos ao responderem a questões iniciais ou finais, explicitaram seu conhecimento prévio sobre os temas abordados e os seus entendimentos e dúvidas após as aulas; elaboraram uma prática interdisciplinar em grupo, com os recursos de um possível guia para a elaboração de uma sequência didática (OLIVEIRA e QUEIROZ, 2013) sobre o tema da flutuação e a vida e, por último, a apresentaram aos demais colegas da turma.

Com objetivo de buscar elementos para análise, a coleta de dados foi realizada via registros em vídeo de modo que os professores, sujeitos da co-docência, pudessem analisar as suas práticas após cada encontro com os alunos e assim pensar nas possíveis mudanças na rota dos planejamentos para as aulas seguintes.

Vale salientar que registros audiovisuais não são evidências do real; são produções quase tão subjetivas e pessoais quanto o diário de campo e isso deve ser levado em conta no momento da análise. A literatura nos aponta algumas possibilidades de referências para o trabalho com videogravação, como Garcez, Duarte e Eisenberg (2011): 
... o uso adequado da imagem em movimento, aliada ao áudio, permite capturar aspectos difíceis de serem captados com outros recursos, tais como expressões corporais, faciais e verbais utilizadas em situações cotidianas (no caso de uma observação sistemática, por exemplo). (GARCEZ, DUARTE e EISENBERG, 2011, p. 251).

O conjunto de informações obtidas nos vídeos possibilitou que elaborássemos episódios contando as histórias dos quatro encontros entre as formadoras (uma de Biologia, que chamaremos de BIO e outra de Física que chamaremos de FIS) e a turma heterogênea de dezessete licenciandos (6 de Biologia, 5 de Física e 5 de Pedagogia).

\section{EPISÓDIOS}

Essa investigação teve no $\mathrm{LIEC}^{1}$ - Laboratório Interdisciplinar Educação em Ciências - um espaço com vetores de força para a linguagem humana em diálogo. Utilizamos a expressão vetores de força com base no pensamento de Bakhtin (2006) quando ele se refere às formas de comunicação ideológicas e afirma que:

O tema e a forma do signo ideológico estão indissoluvelmente ligados e não podem, por certo, diferenciar-se a não ser abstratamente. Tanto é verdade que, em última análise, são as mesmas forças e as mesmas condições que dão vida a ambos. Afinal, são as mesmas condições econômicas que associam um novo elemento da realidade social, que o tornam socialmente pertinente, e são as mesmas forças que criam as formas da comunicação ideológica (cognitiva, artística, religiosa etc.), as quais determinam, por sua vez, as formas da expressão semiótica. (BAKHTIN, 2009, p. 47).

Durante o processo de pesquisa se pôde registrar e compreender o funcionamento discursivo dos sujeitos em episódios de ensino e aprendizagem de ciências, bem como as formas de produção de sentido, texturizadas de valor, a partir de atividades interdisciplinares desenvolvidas no período da formação inicial docente. Para compreender melhor os diferentes lugares de fala na escuta das vozes que dialogam, compreendemos como Bakhtin (2011) que:

ao falar sempre levo em conta o fundo aperceptível da percepção do meu discurso pelo destinatário: até que ponto ele está a par da situação, dispõe de conhecimentos especiais de um dado campo cultural da comunicação; levo em conta as suas concepções e convicções, os seus preconceitos (do meu ponto de vista), as suas simpatias e antipatias - tudo isso irá determinar a ativa compreensão responsiva do meu enunciado por ele. (BAKHTIN, 2011, p. 302).

A ideia dos episódios é ancorada nos conceitos de voz como visão de mundo e enunciado como unidade de comunicação verbal e significação, examinando-se as manifestações discursivas à luz da propriedade dialógica estabelecida por Mikhail Bakhtin, ${ }^{2}$ com a sua abordagem sobre o cronotopo como 
instrumento relevante para proceder a nossa compreensão de sentidos possíveis e inacabados para a materialidade discursiva na co-docência estudada. Logo, o procedimento dessa análise foi colocar a voz do pesquisador em diálogo com outras vozes, entendendo que "um enunciado oral ou escrito se expressa sempre desde um ponto de vista (uma voz) que, para Bakhtin, é mais um processo que uma localização" (CLARK e HOLQUIST apud WERTSCH, 1991, p. 71). Dessa maneira, não há enunciado neutro que não expresse uma visão de mundo. Além disso, o enunciado é composto pelo contexto extraverbal - constituinte necessário de sua estrutura semântica (AMORIM, 2006, p. 107).

Cronotopo é a "interligação das relações temporais e espaciais, artisticamente assimiladas em literatura”. Assim, a teoria de Bakhtin (2014) nos ajuda a entender as conexões de relações temporais e espaciais dos gêneros discursivos, uma vez que a cultura é considerada uma unidade aberta, em constantes transformações. Este conceito, como ressalta Amorim (2004), revela que há sempre um lugar onde "a história se desenrola, onde o tempo passa, se vive e se mede em função das características desse lugar". (p. 223). Dessa maneira, a relação entre cronotopo e a produção do discurso é fundamental e deve ser levada em consideração em qualquer análise a ser realizada. Desde a sua criação em 2013 o LIEC, um laboratório para os cursos de Física, Biologia e Pedagogia, situado no Departamento de Física Aplicada e Termodinâmica de uma universidade pública no Rio de Janeiro e financiado inicialmente pela CAPES/MEC, se propõe a formar professores de forma interdisciplinar.

A relação entre espaço, tempo e cultura presente na ideia de cronotopo nos remete ao Gênero Discursivo. Os gêneros de discurso são tipos relativamente estáveis de enunciados, determinados sócio-historicamente, que se constituem nas esferas da atividade humana. Bakhtin (2011) atenta para a diferença essencial entre gêneros discursivos primários (simples) e secundários (complexos): enquanto os gêneros primários se constituem a partir do cotidiano, os secundários surgem nas condições de convívio cultural mais complexo, desenvolvido e organizado.

Temos então outro conceito chave para nossas análises que incluem atores de diversas áreas de atuação humana - Física, Biologia e Pedagogia, pelo menos, uma vez que em algumas oportunidades professores de outras áreas do conhecimento são convidados. Tais gêneros são postos em diálogo, assumindo que diversos são os significados a serem apropriados e compartilhados dialogicamente.

A riqueza e a diversidade dos gêneros do discurso são infinitas porque são inesgotáveis as possibilidades da multiforme atividade humana e porque em cada campo dessa atividade é integral o repertório de gêneros do discurso, que cresce e se diferencia à medida que se desenvolve e se complexifica um determinado campo (BAKHTIN, 2011, p. 262).

Portanto, diante dos conceitos bakhtinianos trazidos, entendemos que os episódios podem ser escritos, com certo grau de cientificidade, sob dois pontos de vista: o temático como gerador de todos os temas das aulas e o figurativo como representação do espaço (LIEC), tempo (aula) e valor (diálogos). 


\section{ANÁLISES E RESULTADOS}

\section{$1^{\circ}$ Episódio: 0 encontro dos objetos da ciência}

O início das aulas era destinado a que os alunos pudessem responder às perguntas abertas de um questionário sobre os conhecimentos prévios a respeito de questões relacionadas aos conteúdos conceituais. Em um desses momentos, o aluno de Pedagogia elaborou uma pergunta aos professores:

- Essas perguntas podem ser respondidas como nós as entendemos, mesmo que haja outras disciplinas além da Física e da Biologia?

Dois pontos podem ser compreendidos a partir da pergunta feita pelo aluno de Pedagogia: o primeiro diz respeito ao contexto extraverbal que compõe o enunciado - Quem fala? De onde fala? As respostas a essas questões são componentes fundamentais para compreensão do enunciado. Há uma preocupação do aluno com o lugar de onde ele fala que não é nem a Física e nem a Biologia; o segundo ponto se refere ao gênero discursivo formado pelos tipos relativamente estáveis de enunciados associados a esferas da atividade humana. Podemos apontar que há uma preocupação do aluno em se fazer entender, quando imerso em uma situação com a existência de vários gêneros discursivos, entre eles o da Física, da Biologia e da Pedagogia. Como afirma Bakhtin (2011), os enunciados e os gêneros discursivos são correias de transmissão entre a história da sociedade e a história da linguagem. Além disso, segundo Machado (2005), os gêneros, na teoria do dialogismo, estão inseridos na cultura e se manifestam como uma 'memória criativa" e "se constituem a partir de situações cronotópicas" (p. 159).

A professora (FIS) responde à pergunta do aluno:

- Vocês podem e devem responder como entendem, sem perder de vista as concepções interdisciplinares existentes no tema das aulas que é a "Flutuação para a vida do planeta" aproximando-se do ambiente saudável como Direitos Humanos.

No percurso das aulas, cada professora aproveitava a liberdade da codocência para usar os conhecimentos da disciplina da outra, isto é, falar tanto sobre Biologia quanto sobre Física, respeitando as suas especificidades e os seus limites, por meio da complementaridade das ideias e da não neutralidade da ciência.

Alguns exemplos podem ser nitidamente evidenciados nos trechos abaixo, no qual a professora BIO demonstra apropriação de alguns temas curricularmente atribuídos à Física:

- O fitoplâncton está à deriva nos oceanos, pois apesar de ter algum deslocamento, esses microrganismos não conseguem vencer o movimento dessas correntes marítimas. (BIO).

- A luz tem uma importância para entendermos a flutuação, pois a sua penetração nos oceanos vai depender de diversos fatores, como a sua dispersão, absorção causadas pelos microrganismos ou substâncias presentes na água. (BIO). 
A formação de professores de Ciências na perspectiva interdisciplinar sobre a

flutuação para vida no planeta: pelos caminhos da docência

- A entropia disse pra gente isso. O que precisa para sair do estado desorganizado para o estado mais organizado? Ou seja, para construir de algo simples para algo mais complexo, como a fotossintese? (BIO).

Nesse último fragmento, um aluno de Física refletiu e respondeu à professora BIO:

- Nesse caso, a fotossintese precisa de um aporte externo de energia, que é a luq!

Imediatamente, entendendo que seu discurso é direcionado também para sujeitos que não atuam em campos do mesmo Gênero Discursivo, a outra professora complementou com exemplos para que os alunos da Pedagogia pudessem entender a importância da luz para as plantas a partir de uma adequação do discurso, ou seja, trazendo outros elementos e formas que não específicas do gênero discursivo da biologia para que todos pudessem compreender:

- Todo ser vivo respira dia e noite e as plantas respiram e na presença da luz, fazem fotossintese (FIS).

- Poderíamos perguntar a uma criança no ensino fundamental I:O que acontece quando colocamos uma planta dentro de um armário sem luz? (FIS).

Um aluno de Pedagogia responde:

- A planta não sobreviveria por muito tempo. Vai morrer!

Um aluno de Biologia, comparando as diferentes formas de produção de energia para sobrevivência dos seres no nosso planeta, acrescenta:

- Interessante é que o fitoplâncton e as plantas produzem o seu próprio alimento, a glicose e o utilizam pra si, enquanto nós precisamos correr atrás de alimentos.

Outras questões foram discutidas ao longo da dinâmica da aula e aspectos históricos, acompanhados da química e da linguagem matemática foram destacados pelas formadoras como importantes para o entendimento sobre o fitoplâncton e para a vida natural no planeta.

- Eu acho que o ser humano contribuiu pouquíssimo para a vida no planeta, mas sabe-se que as cianobactérias surgiram há mais de 3,5 bilhões de anos na água e foram responsáveis pelas primeiras atividades fotossintéticas e pelo grande evento da presença abundante de oxigênio na atmosfera, entre 2,2 e 2,4 bilhões de anos. (BIO).

- Então, nós temos dois processos de consumo de oxigênio que são: a respiração e a decomposição. Dessa forma, se fižermos um balanço entre a taxa de consumo de oxigênio em 24 h, em algumas condicões mais alteradas e ambientes, teremos valores negativos. (BIO). 
A professora BIO se apropriou da diferença ambiental estudada na Geografia para ilustrar a dimensão, pelo mundo e no nosso país, de um dos problemas naturais provocados pelo fitoplâncton, a floração (aumento exagerado) de algas nocivas. Essa floração impede a passagem da luz na zona eufótica, dificultando o processo fotossintético. Esses problemas têm causas e consequências para a vida natural e econômica do planeta, estando relacionados com a forma como tratamos ou não as águas dos lagos, rios e oceanos.

\section{$2^{\circ}$ Episódio: A ciência dos Direitos Humanos ao ambiente saudável.}

Ao afirmar que "os verdadeiros pulmões do mundo são os oceanos", a professora BIO destaca a importância do fenômeno físico da flutuação do fitoplâncton, enfatizada pelo seu discurso a respeito da presença de luz na camada eufótica dos oceanos. Acrescenta também alguns fatores que podem perturbar consideravelmente a estabilidade do fitoplâncton para permanecer flutuando na região eufótica, região na qual existe a possibilidade de haver fotossíntese, mediante condições físicas e biológicas adequadas.

A professora FIS aproveitou a oportunidade do assunto e relembrou os conceitos sobre o empuxo com os alunos, por meio de um experimento que relaciona empuxo e temperatura:

- A temperatura é um dos fatores que podem alterar a flutuação do fitoplâncton no oceano, pois a densidade da água é alterada em função dela. Posso mostrar, como exemplo prático, o "termômetro de Galileu", pois os objetos flutuantes se deslocam quando a densidade da água é alterada pela temperatura da sua mão ao segurar esse termômetro. (FIS).

Os elementos presentes nesse experimento simples em função da temperatura da água e o seu aumento de volume fez o aluno de Biologia relembrar o aprendido em aula anterior:

- Os objetos descem pois o empuxo é o peso do volume do líquido deslocado pelo corpo e a densidade fica menor por causa do aumento da temperatura na água, diminuindo esse peso e consequentemente o empuxo.

Um aluno da Física questiona:

- Podemos pensar também que as correntes de convecção devido às mudanças de temperaturas nas águas dos oceanos podem deslocar o fitoplâncton?

Ao que FIS respondeu que sim, afirmando ainda que outros fatores também possam contribuir bastante para a dificuldade da flutuação do fitoplâncton, como a floração de algas nocivas que impede a passagem da luz nessa região, dificultando consequentemente o processo fotossintético. A professora BIO apresentou imagens da costa em Dubai, cidade de alto poder econômico, atingida pelo fenômeno da floração, provavelmente causado pelo tratamento inadequado 
do esgoto local. Mostrou ainda um slide que explica o processo de eutrofização, gerado por poluição no meio aquático que possibilita o aumento de nutrientes e o crescimento de microrganismos nocivos.

Nesse momento, a professora FIS, relembrando uma dúvida que tivera durante a fase de planejamento da sequência didática, surgiu com uma questão a respeito desse exemplo em Dubai:

- Quando eu estava estudando essa questão com a professora BIO, fiz uma pergunta bem curiosa e gostaria de compartilhar e saber o que vocês pensam: Se essas algas são organismos vivos e fazem fotossintese e assim geram mais oxigênio na atmosfera também, então quanto mais dejetos orgânicos lançados no mar, melhor. Não é? (FIS).

Houve um reboliço nas respostas entre os alunos, sem qualquer consenso de ideias, levando as professoras BIO e FIS a interferirem nas discussões, corrigindo as respostas e explicando que o aumento de dejetos gera sim uma maior produção de oxigênio, mas ao mesmo tempo leva à morte desses microrganismos, criando uma barreira que impede a passagem da luz para a realização da fotossíntese, enfraquecendo e até paralisando o processo.

Um aluno de Biologia demonstrando interdisciplinaridade entre ciências da natureza e ciências sociais pergunta:

- E, como se resolve esse problema?

BIO responde que a atitude humana é fundamental para resolver esse problema, a partir de sistemas eficazes para o tratamento do esgoto e da água. E acrescenta que Dubai, local no qual as demandas sociais são ouvidas, já está pensando nas possibilidades de projetos nesse sentido. Apresenta ainda por slides o mapeamento de florações de microrganismos nocivos pelo mundo e destaca casos no Rio de Janeiro e no Brasil que, ao longo do tempo, só têm sido divulgados quando a população se incomoda, reclama e é ouvida, ao menos pela mídia, merecendo então a atenção de políticos e dirigentes.

Um aluno da Física, relacionando o tema estudado à saúde humana, pergunta à professora $\mathrm{BIO}$ :

- Essas coloracõos esverdeadas, avermelhadas e marrons na água são toxinas que podem causar irritabilidade na pele humana?

Ao que $\mathrm{BIO}$ responde que a coloração mostra que existe floração e que algumas podem produzir toxinas sim, acrescentando que não é aconselhável entrar em contato com a água nessas condições, pois há toxinas de efeito dermatotóxico, neurotóxico ou hepatotóxico, que podem causar irritabilidade na pele humana e até a morte, sob outra forma de contato. Ressalta ainda que inclusive ocorreu a morte de seres humanos no tratamento de hemodiálise em Pernambuco, no Brasil, causada por cianobactérias nocivas e tóxicas, com água recolhida em reservatórios locais, como os açudes, trazendo a questão dos direitos humanos ao enfatizar que: 
- É isso aí! A água deve ser um direito de todos, pois é um dos componentes no ambiente saudável. Assim como aconteceu esse problema na região nordeste do Brasil, em outros locais no mundo isso também ocorre. Então, é preciso pensar nos direitos de um ambiente saudável para todos e considerarmos inclusive, os componentes sociais, do acesso à água potável [...] BIO.

Em seu discurso, BIO continua o debate com os alunos sobre a temática da comercialização da água e o direito de todos por esse elemento tão essencial para vida humana e de outros seres vivos no planeta.

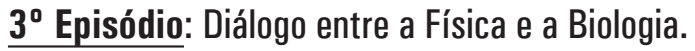

A partir das imagens nos slides que mostravam as dimensões de uma colorida e bonita variedade de fitoplâncton e as cadeias formadas por várias células, as professoras BIO e FIS abriram uma série de discussões com os alunos sobre as características, movimentação e sensibilidade aos fenômenos luminosos e magnéticos mais intensos dessa forma de vida aquática. Entretanto, o recorte dos professores nesse momento foi mostrar inúmeros formatos desses microrganismos quanto à presença de óleos graxos no interior das células que serviam como reserva de energia, facilitando ao mesmo tempo a produção de oxigênio via fotossíntese. Nesse momento, a professora BIO pergunta para os alunos:

\section{- O que isso tem a ver com a futuação?}

Aproveitando a oportunidade, a professora FIS retoma suscintamente a ideia de líquidos que não se misturam, como óleo e água. Instantaneamente, os alunos associaram os conceitos de empuxo e densidade com as características relacionadas à flutuação desses microrganismos na zona eufótica da coluna d'água dos oceanos. A Matemática é então trazida de forma explícita, na forma de uma equação, apresentada em um slide no qual havia elementos que puderam evidenciar ações de complementaridade das áreas do conhecimento: de um lado, a Física apropriando-se de uma equação matemática (equação de Stokes) ${ }^{3}$ para calcular a velocidade de sedimentação de uma partícula esférica e do outro lado a Biologia acrescentando um fator empírico relativo à forma desses microrganismos, como variável importante na medida da velocidade com que eles caem e se sedimentam no solo: quanto mais a forma se afasta da forma esférica, simétrica, maior o fator e menor a velocidade de sedimentação, melhorando a flutuação na zona eufótica.

Diante da fórmula matemática houve uma sonorização de espanto e foi possível até ouvir isoladamente: "Meu Deus, isso é grego pra mim!”, caracterizando o contato dos alunos, de Pedagogia e mesmo alguns de Biologia, com um gênero discursivo desconhecido. Logo, a professora FIS sentiu necessidade de apresentar de forma muito simples o conceito de velocidade, com o auxílio de exemplos do nosso cotidiano, levando a fórmula que relaciona o espaço percorrido pelo tempo gasto em percorrê-lo, mostrando aos alunos o comportamento das grandezas direta ou inversamente proporcionais à velocidade na equação de Stokes.

A atenção e o silêncio dos alunos sinalizavam a possibilidade na compreensão dos conceitos apresentados por FIS. Vale destacar que para Bakhtin o ouvinte que recebe a enunciação é dotado de uma atitude responsiva ativa - concorda ou 
discorda - e que o silêncio é uma forma de resposta e pode ser analisado a partir da expressão facial, por exemplo. Assim, "toda compreensão da fala viva, do enunciado vivo é de natureza ativamente responsiva (...); toda compreensão é prenhe de resposta, e nessa ou naquela forma a gera obrigatoriamente: o ouvinte se torna falante" (BAKHTIN, 2011, p. 271). Nesse sentido, os enunciados são entendidos como construções que consideram o ouvinte (destinatário do discurso) ao qual se destinam - direcionalidade - e o contexto no qual são produzidos. Wertsch (1991) nos mostra que "nenhum enunciado, e consequentemente nenhuma de nossas ações, se encontra isento das determinações que os cenários socioculturais, através dos instrumentos mediadores que eles mesmos provêm, nos impõem” (p. 13).

Assim, após serem apresentados os elementos da fórmula de Stokes, descrevendo cada grandeza física constituinte, como a aceleração da gravidade local, a densidade do líquido e do microrganismo e a sua geometria (tamanho), além do coeficiente de viscosidade do meio, lançou-se uma pergunta aos alunos:

- Olhando para essa fórmula, o que nos chama a atenção para que se possa reduzir a velocidade de sedimentação num processo evolutivo durante o tempo? (BIO).

Os alunos da Física e da Biologia responderam simultaneamente que se diminuíssem os valores de duas grandezas físicas, a densidade e o tamanho do microrganismo, diminuiria a sua velocidade de sedimentação, demonstrando, de alguma maneira, que os termos utilizados pelas professoras e seus significados já haviam sido apropriados. Entretanto, a professora BIO retoma a fórmula de Stokes, apontando para os alunos que a variável tamanho é indicada por $\mathrm{d}^{2}$ (diâmetro da partícula elevado ao quadrado), portanto própria para formatos circulares ou semicirculares. BIO provoca os alunos com a lembrança das imagens nos slides que mostram os microrganismos e faz uma outra pergunta:

\section{- Vocês viram formas circulares ou semicirculares nas imagens desse fitoplâncton? (BIO)}

Os alunos foram uníssonos respondendo que não, ao que BIO sucede afirmando que apesar da fórmula de Stokes mostrar que se reduzíssemos o tamanho dos microrganismos aumentaríamos a flutuação, reduzindo a velocidade de sedimentação, outro problema ocorreria com eles: os microrganismos serviriam de alimento para o zooplâncton, o que ocasionaria uma redução de sua população ou exterminação. Continua perguntando para os alunos:

\section{- Devemos então pensar numa saída para o problema com as formas, uma vez que o fitoplâncton} não tem todo ele a mesma forma. (BIO).

A professora FIS disse 'delicadamente' que "a Biologia foi lá e consertou a fórmula da Física”, mostrando para os alunos a inserção de um fator chamado coeficiente de resistência pela forma que evidencia a existência de algumas formas que têm mais ou menos facilidade de sedimentação (afundamento). Esse diálogo entre a Física e a Biologia se aproxima do sentido dialógico proposto por Bakhtin pois se caracteriza pela ideia oposta ao conhecimento monológico: 
Por mais monológico que seja o enunciado (por exemplo, uma obra científica ou filosófica), por mais concentrado que esteja no seu objeto, não pode deixar de ser em certa medida também uma resposta àquilo que já foi dito sobre dado objeto, sobre dada questão, ainda que essa responsividade não tenha adquirido uma nítida expressão externa: ela irá manifestar-se na tonalidade do sentido, na tonalidade da expressão, na tonalidade do estilo, nos matizes mais sutis da composição. (BAKHTIN, 2011, p. 298)

A interdisciplinaridade na construção desse conhecimento científico levou à reflexão sobre a prática científica, tendo a professora FIS discutido com o grupo de alunos uma importante questão sobre a Natureza da Ciência.

- O que vem primeiro: a teoria ou a observação? (FIS)

Em seguida FIS relata algumas pesquisas de Biologia comportamental animal que se apropriaram de metodologias que utilizam a modelagem matemática previamente à empiria, mostrando que, antes de ir a campo os cientistas elaboram equações diferenciais teóricas envolvendo os elementos favoráveis e desfavoráveis à procriação de determinados grupos de animais.

Buscamos em Praia et al (2002), o papel do professor que percebe a prática científica, procurando analisar e refletir os resultados, à luz do quadro teórico e das hipóteses enunciadas, levando em conta os contextos culturais, históricos e sociais da construção e da produção científica. O autor enfatiza que:

Numa perspectiva racionalista, enquanto programa de investigação progressivo, a experiência científica deve ser guiada por uma hipótese, que procura funcionar, sobretudo, como tentativa da sua retificação e questionamento - ela interroga, problematiza conduzindo, muitas vezes, a outras hipóteses. Trata-se de um diálogo entre hipóteses/ teorias e a própria experimentação, diálogo nem sempre simples, já que, também aqui, o confronto entre o teórico (o idealizado) e a prática (o realizado) se interligam. Reside aqui, pensamos, uma das riquezas heurísticas da experimentação. Se a hipótese intervém ativamente nas explicações que os resultados da experiência sugerem, a teoria tem um papel primordial na avaliação dos resultados obtidos. (PRAIA et al, p.257, 2002).

Acreditamos que na formação de professores seja possível articular a epistemologia e a didática para que tenhamos a teoria e prática como uma unidade intrínseca de ensino e pesquisa.

\section{Episódio: Ensinando PCK}

Como encaminhamento para a produção pelos alunos de seus PCK em grupo, nesse episódio as professoras utilizaram uma sondagem como disparador de interesse no início da aula, oportunizando que os licenciandos se manifestassem oralmente com os seus relatos de experiências docentes, a partir de situações cronotópicas, aproximadas à construção interdisciplinar.

Um aluno da Biologia relatou: 
A formação de professores de Ciências na perspectiva interdisciplinar sobre a

flutuação para vida no planeta: pelos caminhos da docência

- Eu conheço um amigo de profissão, só que ele é da Química e a gente estava falando sobre a Bioquímica, sobre proteina. E ao mesmo tempo que en falava de proteina formada por um conjunto de aminoácidos, ele já mostrava a função desses aminoácidos. E o exemplo que ele deu foi o cabelo dos negros ter mais aminoácido cisteina e por isso que é enroladinho e continuou falando das pontes de sulfeto. E a gente estava até pensando em fazer um projeto interdisciplinar, por exemplo no sistema digestório eu vou falar do processo mecânico da digestão que ocorre na boca a partir da mastigação e ele vai falar dos processos químicos que ocorrem ali e que estão relacionados às enzimas salivares.

A professora FIS perguntou a ele se essa iniciativa teve alguma relação com a disciplina eletiva em questão, ao que ele respondeu

- Foi depois sim, esse ano que começou a abrir mais os meus olhos. Lembra que eu estava lendo o livro "O velho e o mar"? E aí eu comecei a enxergar ali como a Física, a questão do empuxo, da flutuação do barco, a questão biológica do peixe e tudo mais, a literatura ali, a arte com as imagens. Uma série de questões diferentes envolvidas naquele livro uma coisa multidisciplinar.

Um aluno da Física relatou:

- Eu fir iniciação da ciência com a Química, a Física e a Biologia em uma escola estadual bá algum tempo aqui no entorno, realizando projetos, experimentos, aulas, palestras, quando bavia - PIBID e hoje não tem mais. E realizávamos várias ações coletivas, como horta, composteiras...

Outro aluno da Biologia pediu para dar o seu relato:

- No colégio lá que eu trabalho, a gente realizou um 'aulão' com os professores de Física e Biologia sobre as questões das hidrelétricas e as variáveis que interferem na vida das espécies daquele lugar, a alteração do curso dos rios. Citamos o caso em Belo Monte.

Uma pergunta demonstrando interesse pedagógico foi realizada por um aluno da Física sobre a ação docente interdisciplinar:

- A interdisciplinaridade acontece entre professores de diferentes áreas ou pode ser também um só professor abordando temas diferentes?

A professora FIS respondeu ao aluno que existe a interdisciplinaridade com um professor apenas, mas exige dessa pessoa mais tempo e mais fontes para informações e conhecimento. A professora BIO esclareceu que há determinados assuntos abordados na Biologia ou na Física em que algumas questões surgirão com possibilidades para o trabalho interdisciplinar, constituindo um novo discurso que abarca pelo menos dois Gêneros Discursivos, o da Física e o da Biologia.

O mesmo aluno da Física se recorda de uma experiência interdisciplinar em sala de aula e disse: 
- Tive que dar uma aula sobre Galileu e falei sobre os aspectos históricos no Renascimento, as pinturas relacionadas à observação dos astros, a história do telescópio. Eu trabalhei a arte e a literatura com o auxílio de um livro de Galileu chamado "Diálogo sobre duas novas ciências".

A professora FIS forneceu exemplos sobre as pesquisas científicas que aproximam a interdisciplinaridade por meio da parceria de professores de diferentes áreas do conhecimento e que desejam constituir projetos pedagógicos de ensino de ciências na escola. Ela salienta que a ação de co-docência com possibilidades de abordagens interdisciplinares é uma forma de trabalho para além da parceria, pois exige a presença de dois ou mais docentes no mesmo espaço escolar e comenta que esse processo tem surgido também na formação de professores possibilitando co-aprendizagens:

- É isso que estou fazendo com a BIO. É uma docência em conjunto, cada uma com a sua base mais forte de sua disciplina, mas com isso eu já aprendi muito e com ela e acredito que vice-versa também. [...] essa visão de ensino é que a gente não tem na nossa cultura, onde o professor está aprendendo o tempo todo. É a profissão de quem quer aprender e para isso resolveu ensinar. Essa é a nossa profissão! (FIS)

Os relatos dos licenciandos serviram para contextualizar a necessidade de aprendizagens para além da sua própria disciplina na elaboração de projetos educativos. Como um dos objetivos específicos na formação docente é ensinar ao futuro professor a importância na organização da prática em função dos conteúdos conceituais, procedimentais e atitudinais, a abordagem PCK foi a escolhida pelas professoras, como uma oportunidade para os licenciandos aprenderem a compor as ações pedagógicas no desenvolvimento de seus projetos educativos.

No sentido de planejarem em conjunto projetos pedagógicos, a professora FIS solicitou que os alunos formassem três grupos heterogêneos por curso para pensarem na elaboração de um projeto por grupo com abordagem interdisciplinar sobre o tema Flutuação e Vida, levando em conta um dos grandes desafios da escola que é o trabalho com as questões sobre os Direitos Humanos. Ela provocou os alunos com a pergunta: O que podemos fazer para formar cidadãos que possam refletir e tratar as questões relacionadas com as desigualdades sociais, aos problemas ambientais, de gênero, de raça e outras mais?

Durante o momento de discussões iniciais, cada grupo manifestou o seu interesse no desenvolvimento de projetos, trazendo as suas dúvidas em relação às estratégias de ensino, ao tempo de aula no desenvolvimento dos conteúdos, à utilização dos recursos didáticos e à busca dos objetivos epistemológicos para o tema escolhido. Um aluno da Física ressaltou a produção de tecnologia e os fatores que afetam a sociedade, dizendo que:

- Pensamos em trabalhar ciência como construção humana. A ciência está evoluindo pelo próprio investimento que está inserido nela. E esse investimento é para melhorar a técnica, o processo. Mas, isso consequentemente afeta a produção. 
A professora $\mathrm{BIO}$ sugeriu que o grupo pudesse registrar essas ideias no seu planejamento e ainda recomendou que as questões relacionadas à produção de tecnologia pudessem dialogar com as formas de energia limpa na abordagem CTS-A e/ou com a Natureza das Ciências.

A partir dessas questões, houve todo o cuidado da professora FIS ao mostrar detalhadamente em slides para os alunos uma sugestão de planejamento e elaboração de projetos educativos na abordagem CTS e Arte (OLIVEIRA e QUEIROZ, 2013), explicando que a problemática inicial para o projeto pode ser representada pela Arte e que as técnicas envolvidas nesse processo fornecem elementos para saber qual é a ciência que se faz presente e assim conceber as construções pelos alunos de um produto retornável à sociedade com possíveis soluções.

Todo conjunto de ideias sofreu a tensão das aspirações de cada grupo de trabalho até culminar no procedimento das ações docentes na perspectiva do conhecimento pedagógico do conteúdo - PCK. Talanquer (2004) afirma que os programas de formação inicial devem colaborar com a construção do PCK dos futuros professores:

\footnotetext{
Um bom programa de formação docente deve proporcionar uma preparação disciplinar e pedagógica sólida. [...] Os programas de formação e atualização docente necessitam abrir espaços para que as peças chaves do conteúdo a ser ensinado sejam sujeitas à análise e discussão didática e pedagógica. [...] Este tipo de reflexão não só ajudaria os professores em formação a desenvolver seu PCK, como também a capacidade crítica e as habilidades analíticas que lhes permitiriam conceber a aula como um espaço de exploração e investigação contínua (TALANQUER, 2004, p. 64-65).
}

Acreditamos que a prática docente oportunize ser acessada e retratada quando pensamos no desenvolvimento do PCK e na formação inicial. Na sequência dessa pesquisa avaliaremos os diversos PCK elaborados pelos licenciandos.

\section{CONSIDERAC̣ÕES}

Nesse trabalho ampliamos o nosso entendimento sobre a co-docência como estratégia de ensino ao analisarmos os processos de construção dos saberes docentes na perspectiva interdisciplinar no agir profissional. Oportunizamos também que os alunos em formação se façam futuros profissionais na relação com outros seres humanos, com colegas de outras formações disciplinares, construindo novas compreensões da ação docente que valorize os direitos humanos.

O volume e a riqueza das informações nas videogravações dessa investigação podem ampliar outras discussões para além das questões propostas para esse artigo, mas escolhemos selecionar os elementos que nos ajudaram a entender as possibilidades da co-docência na aprendizagem dos professores formadores e dos licenciandos. Partimos do pressuposto de que a atitude pedagógica para esse tipo de trabalho depende basicamente da vontade ideológica, além da confiança no outro e no objeto de estudo que ambos se propõem a desenvolver colaborativa e dialogicamente. 
Essa investigação procurou aproveitar os elementos valorados que emergiram nos discursos de todos os atores (licenciandos e professores formadores) e nas suas ações colaborativas durante a dinâmica das aulas no LIEC. É nesse mesmo espaço formal que devemos ressaltar a sua força destinada a potencializar o processo de formação profissional docente com a perspectiva interdisciplinar. Vale ressaltar aqui que todo enunciado é uma escolha e está carregado de valor:

$\mathrm{Na}$ realidade, não são palavras o que pronunciamos ou escutamos, mas verdades ou mentiras, coisas boas ou más, importantes ou triviais, agradáveis ou desagradáveis etc. A palavra está sempre carregada de um conteúdo ou de um sentido ideológico ou vivencial (BAKHTIN, 2006, p. 98/99).

A existência de obstáculos na realização desse trabalho é inerente, assim que se inicia o ato do encontro das ideias entre pares, pois o tempo é ocupado pelo cotidiano das nossas individualidades com as atividades profissionais. Mas, estamos falando de vontade ideológica que inspira a ação, logo seria um desperdício perder essa oportunidade de apresentar nossas primeiras análises que possibilitam construir o conjunto de uma obra e permitir que ela fique sempre inacabada, porém ativamente disponível para outros atores pensarem em projetos interdisciplinares na formação de futuros professores.

As pesquisas na formação docente apontam a necessidade de aprofundarmos ainda mais os nossos estudos sobre as oportunidades de diálogo entre as áreas do conhecimento por duas ou mais vozes e a coaprendizagem dessa ação. Houve momentos no processo em que ficou claro a existência de diálogos prévios às aulas entre as professoras para a construção de um enunciado visando ao horizonte social. As dúvidas sanadas durante os encontros de planejamento entre as formadoras geraram questões colocadas para os alunos, como foi o caso da dúvida sobre o aumento dos dejetos e a maior produção de oxigênio, explicitado no $2^{\circ}$ episódio, quando a professora FIS relata aos estudantes sua dúvida em relação à fotossíntese do fitoplâncton poder aumentar e consequentemente purificar melhor o ar, sem levar em conta o autossombreamento provocado pelo crescimento descontrolado, ocasionado pelo aumento de esgoto lançado às águas.

Outro aspecto relevante foram os relatos de experiências na perspectiva interdisciplinar apresentados pelos licenciandos no $4^{\circ}$ episódio, que apontaram a necessidade de aprendizagem tanto disciplinar quanto interdisciplinar durante o planejamento das atividades pedagógicas. A partir dessa situação, os formadores aproveitaram para estimular a elaboração de planejamentos na abordagem PCK.

Ainda sobre a interdisciplinaridade, entendemos que as possibilidades de parceria podem ser potencializadas quando pensadas a partir das ideias de Bakhtin. O conceito de Gênero Discursivo associado ao de Cronotopo ajuda a buscar construções de projetos que levem em consideração não apenas a adequação de conceitos, mas também a preocupação com a linguagem, a epistemologia e a metodologia na ciência e na forma como se desenvolvem as atividades didáticas que envolvem mais de uma área de conhecimento.

Como a oportunidade não pode ser desperdiçada, aproveitamos para ousar, dizendo que os espaços precisam ser ocupados para desenvolvermos trabalhos que 
A formação de professores de Ciências na perspectiva interdisciplinar sobre a

flutuação para vida no planeta: pelos caminhos da docência

possam contribuir para a qualidade na formação profissional docente e co-docente. Entretanto, a realidade nos cursos de licenciatura é ainda bastante tímida nesse sentido e essas ações institucionais ocorrem de forma sazonal e eletiva no currículo, ofuscando a força em potencial do LIEC e de outros ambientes formativos similares.

\section{REFERÊNCIAS}

AMORIM, M. Cronotopo e Exotopia In: BRAIT, B. (org.) Bakhtin: outros conceitos-chave. São Paulo: Contexto, 2006.

BAKHTIN, M. Estética da criação verbal. 6a ed. São Paulo: Editora WMF Martins Fontes, 2011. BAKHTIN, M. (Volochínov). Marxismo e Filosofia da Linguagem. 12a Ed. São Paulo: Hucitec, 2006.

BAKHTIN, M., 1895-1975. Questões de literatura e estética: a teoria do romance; tradução de Aurora Fornoni Bernardinini... [et al]. $7^{\text {a }}$ ed. São Paulo: Heucitec, 2014.

CACHAPUZ, A., GIL-PÉREZ, D., CARVALHO, A. D., PRAIA, J., \& VILCHES, A. A necessária renovação do ensino das ciências. São Paulo: Cortez, 2005.

CACHAPUZ, A.; PRAIA, J.; JORGE, M. Da educação em ciência às orientações para o ensino das ciências: um repensar epistemológico. Ciência \& Educação, v. 10, n. 3, p. 363-381, 2004.

CASTRO, G. F.; QUEIROZ, G. A formação inicial de professores de física a partir da prática de projetos. In: VI Encontro Nacional de Pesquisa em Educação em Ciências - VI ENPEC, 2007, Florianópolis, Santa Catarina. Anais... Florianópolis, Santa Catarina: ABRAPEC, 2007.

CHASSOT, A. Alfabetização científica: questões e desafios para a educação. Ijuí: Ed. UNIJUÍ, 2006.

CARVALHO, A. M. Metodologia de pesquisa em ensino de física: uma proposta para estudar os processos de ensino e aprendizagem. In: Encontro de Pesquisa em Ensino de Física, 9., 2004, Jaboticatubas, MG. Anais...Jaboticatubas, MG: Sociedade Brasileira de Física, 2004.

FAZENDA, I. Interdisciplinaridade: Didática, Prática de Ensino e Direitos Humanos? XVII ENDIPE/2014. São Paulo, 2014.

GARCEZ, A.; DUARTE, R.; EISENBERG, Z. Produção e análise de vídeogravações em pesquisas qualitativas. Educação e Pesquisa, v. 37, n. 2, p. 249-261, 2011.

GIL-PÉREZ, D.; CARVALHO, A.M.P. de. Formação de professores de ciências: tendências e inovações. Daniel Gil Perez, Ana Maria Pessoa de Carvalho, v. 5, 1993.

MACHADO, I. Gêneros Discursivos IN: BRAIT, B. (org.) Bakhtin: conceitos-chave. $2^{\mathrm{a}}$ ed. São Paulo: Contexto, 2005.

OLIVEIRA, R.; QUEIROZ, G. CTS-Arte: uma possibilidade de utilização da arte em aulas de Ciências. Conhecimento \& Diversidade, Niterói, n. 9, p. 90-98 jan./jun. 2013.

PADISÁK, J.; SORÓCZKI-PINTÉR, É.; REZNER, Z. Sinking properties of some phytoplankton shapes and the relation of form resistance to morphological diversity of plankton-an experimental study. In: Aquatic biodiversity. Springer, Dordrecht, 2003. p. 243-257.

POMBO, O. A Escola, a Recta e o Círculo. Lisboa: Relógio d’Água, 2002.

PRAIA, J.; CACHAPUZ, A.; GIL-PÉREZ, D. A hipótese e a experiência científica em educação em ciência: contributos para uma reorientação epistemológica. Ciência \& Educação (Bauru), v. 8, n. 
2, p. 253-262, 2002.

PRETTO, N. Polêmicas contemporâneas: formando professores ativistas comprometidos com a sociedade. 2017.

QUEIROZ, G. R. P. C.; DOMINGOS, P. Flutuação dos corpos e a vida. In: Silvania Nascimento e Mara Regina Batista. (Org.). Interdisciplinaridade para além da sala de aula. Belo Horizonte: ROLIMÃ, v. único, p. 39-57, 2017.

ROITMAN, I. Educação científica: quanto mais cedo, melhor. Brasília: RITLA, 2007.

ROTH, W.; BOYD, N. Co-teaching, as co-learning, is praxis. Research in Science Education, v. 29, n. 1, p. 51-67, 1999.

SCHÖN, D. A. Educando o Profissional Reflexivo - um novo design para o ensino e a aprendizagem. Porto Alegre: Artmed Editora, 2000

SHULMAN, L. S. Knowledge and teaching: foundations of a new reform. Harvard Educational Review, Harvard, v. 57, n. 1, p. 1-22, 1987.

TALANQUER, V. Formación docente: ¿Qué conocimiento distingue a los buenos maestros de química? Educación química, v. 15, n. 1, p. 52-58, 2004.

WERTSCH, J. V. Voces de la mente: um enfoque sociocultural para el estúdio de la accion mediada. Madri: Aprendizaje Visor, 1991.

\section{NOTAS}

1 LIEC - Laboratório Interdisciplinar Educação em Ciências, constituído pelo Programa LIFE (Programa de Apoio a Laboratórios Interdisciplinares para a formação de educadores) da CAPES/ MEC. Leia: http://www.capes.gov.br/educacao-basica/life.

2 Mikhail Bakhtin (1895-1975), autor de obras determinantes sobre a poética de Dostoievski e de Rabelais. Ao que parece, Bakhtin recusava-se a fazer concessões à fraseologia da época e a certos dogmas impostos aos autores.

3 A velocidade de sedimentação de espécies de algas através de um meio fluído pode ser descrita pela equação de Stokes modificada: $v_{S}=\frac{2 g d^{2}\left(\rho^{\prime}-\rho\right)}{9 \eta}$

Onde: $v_{s}\left(\mathrm{~m} \mathrm{~s}^{-1}\right)$ é a velocidade de sedimentação, $g\left(\mathrm{~m} \mathrm{~s}^{-2}\right)$ é a aceleração gravitacional, $d(\mathrm{~m})$ é o diâmetro de uma esfera de volume idêntico ao da alga, $\rho$ 'é a densidade específica da alga que está sedimentando $\left(\mathrm{kg} \mathrm{m}^{-3}\right), \rho$ é a densidade do meio fluido $\left(\mathrm{kg} \mathrm{m}^{-3}\right), \eta$ é a viscosidade do meio $\left(\mathrm{kg} \mathrm{m}^{-1} \mathrm{~s}^{-1}\right)$ e $\Phi$ é o fator da resistência pela forma à sedimentação. Este é um número adimensional que expressa o fator pelo qual a velocidade de sedimentação de uma partícula qualquer difere da de uma esfera de volume e densidade idênticos (PADISÁK et al. 2003).

Submetido em 11/10/2018

Aprovado em 13/03/2019

\section{Contato:}

Rua Tomás Coelho, $\mathrm{n}^{0} 34 / 105$

CEP 20.540-110 - Rio de Janeiro - RJ, Brasil 